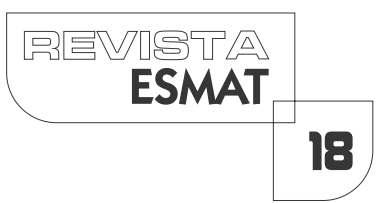

\title{
ESTADO DE DIREITO, EXERCÍCIO DA GESTÃO PÚBLICA E OS SEUS CONTROLOS 1
}

RULE OF LAW, THE EXERCISE OF PUBLIC MANAGEMENT AND ITS CONTROLS

José Mouraz Lopes

Doutor em Direito, Justiça e Cidadania pela Faculdade de Direito e Economia da Universidade de Coimbra. Juiz conselheiro no Tribunal de Contas.

\section{RESUMO}

A partir de uma análise da fragilidade de controlos que estiveram na origem das crises económicas e sociais após 2008 e das suas consequências para os cidadãos, efetua-se uma abordagem sobre a relevância dos plúrimos controlos que devem convocar a gestão pública, no âmbito do Estado de Direito. Aos vários poderes de controlo é exigido um papel essencial, ainda que executados em perspectivas e níveis diferentes e por atores diferenciados. Desenvolvem-se os mecanismos de controlo social, constitucional, administrativo, financeiro e criminal, enquadrados numa dimensão transnacional, pública e privada, que leve em conta as exigências de transparência devida aos cidadãos.

PALAVRAS-CHAVE: Estado de Direito; Gestão pública; Controles.

\section{ABSTRACT}

From an analysis of the fragility of controls that led to the economic and social crises after 2008 and their consequences for citizens, an approach is taken over the relevance of the multitude of controls that should be called upon by public administration within the Rule of Law. The various powers of control are required to play an essential role, even if performed at different perspectives and levels and by different actors. Social, constitutional, administrative, financial and criminal control mechanisms are developed, framed in a public and private transnational dimension, taking into account the demands of transparency due to citizens.

KEYWORDS: Rule of Law; Public management; Controls.

I O presente artigo tem por base uma intervenção pública efetuada no II Congresso Internacional de Desempenho do Setor Público (CIDESP), ocorrido em Florianópolis, Brasil, em agosto de 2018. 


\section{O OVO DA SERPENTE}

Estado de Direito é a expressão prática do modelo de governação política onde o governo das leis é exercido mediante o estabelecimento de limites jurídicos que não podem ser ultrapassados.

Questão, historicamente discutida, é saber que tipo de leis ou de lei enquadra a atuação de um governo ou da administração, qual a sua amplitude e quais os seus limites.

Mas, também, quais os limites de quem zela para que sejam cumpridos e, em último termo, qual o papel da justiça e da jurisdição nesse debate.

Essa é uma discussão teórica que percorreu todo o século $X X$, nomeadamente após a subida de Hitler ao poder, por meio das urnas e, sobretudo, da trágica aniquilação das leis legitimada nessa "vontade popular", sem que, qualquer poder, no qual se inclui o poder judicial, se the opusesse.

Outros exemplos menos trágicos poderiam ser referidos, tanto na Europa como noutras partes do mundo onde o conceito de lei (e o seu estrito cumprimento) serviu governos, muitas vezes com suporte dos tribunais, para reduzirem os direitos fundamentais dos cidadãos a meros objetivos de concretização no longo prazo. As várias, e ideologicamente diversas, ditaduras, demonstram a relevância do problema. A justiça esteve sempre, nessas situações, reduzida a uma caricatura de justiça.

Evidencia-nos a história que é nos momentos difíceis ou extremos do exercício político que a arquitetura jurídico-constitucional que define os poderes, o seu grau de autonomia e os controlos mútuos é testada na sua validade teórica.

E o que são os momentos difíceis ou extremos? São, numa aproximação simplificadora, todos aqueles em que os consensos legitimadores das decisões não existem ou se apresentam como muito frágeis.

As quebras «constitucionais», algumas transições de regimes políticos ou as crises sociais são exemplos dessa fragilização.

Estas últimas, já neste século, têm assumido uma impressividade extraordinária, nomeadamente pela intranquilidade pública que comportam e, sobretudo, pelas fraturas sociais que lhe são imanentes.

Desde os finais dos anos 90 do século passado foi percetível como o «ovo da serpente», a "captura" dos Estados e das instituições que conformam o Estado de Direito por um rasto de patologias diversificadas foram se avolumando.

$\bigcirc$ apoderamento do sistema político pelo mundo financeiro, a apologia da autorregulação das instituições financeiras sem controlos públicos ${ }^{2}$, a circulação de capitais

2 Sobre as responsabilidades das entidades financeiras que levaram à crise de 2008, o relatório La Rosière, de 25 de fevereiro de 2009, relativo à supervisão financeira na Europa nos anos que antecederam a crise de 2008, evidencia os altíssimos valores dos esquemas em que se viram envolvidas as entidades financeiras europeias (Disponível em http://ec.europa.eu/ internal_market/finances/docs/de larosiere_report_en.pdf) 
e instrumentos financeiros sem questionamento sobre as suas origens e destinos, as cumplicidades entre quem desempenhava funções públicas e privadas, o esbatimento das regras que impedem conflitos de interesses e, sobretudo, a expansão da corrupção por várias áreas da sociedade são exemplos de tais patologias.

A economia se converteu na razão essencial do discurso público e privado, da governação pública ${ }^{3}$ e, consequentemente, da própria vida diária dos cidadãos.

Os mercados e os seus representantes, atuando como «principais» atores económicos, tornaram-se uma espécie de dogma, com alguma dimensão de personagens «intocáveis».

Dir-se-ia, como referem alguns autores, que a economia se elevou ao «estado de "valor", equivalendo-se e, nalguns casos, substituindo valores institucionais ${ }^{4}$, como a virtude, a responsabilidade ou tão só a lealdade.

Simultaneamente emergiu, com alguma força, um discurso público de deslegitimação sobre as instituições que pretendiam fazer o seu trabalho de regulação e controlo e, concretamente, os Tribunais ou o Ministério Público.

Sobre isto o exemplo italiano é paradigmático ${ }^{5}$. Sistematicamente os Tribunais eram apelidados, no mínimo, de forças de "bloqueio" quando, no exercício das suas funções, controlavam a aplicação das leis no domínio financeiro, administrativo ou mesmo, em ultima ratio, no domínio penal. Itália foi apenas o início. Espanha, Argentina, Brasil, são exemplos de situações espelho que ocorreram noutras partes do globo.

Tratava-se, em todas estas situações, de um discurso que via (e vê) na lei e no direito, e quem as faz cumprir, obstáculos ao laisser faire, laisser passer, que, ainda que diversificado de país para país ou de conjuntura para conjuntura, sistematicamente emergia (e continua a emergir) em determinadas áreas sociais e políticas. Um discurso que se sustenta na afirmação de uma regulação social ou controlo mínimo e que vê quase sempre nas instituições formais de controlo um obstáculo ao desenvolvimento, entendido este como algo que depende apenas e só da iniciativa individual, pessoal ou coletiva, territorialmente circunscrita e sem preocupação de sustentabilidade global.

3 Sublinhando esta situação, no domínio da educação, com repercussões negativas numa verdadeira educação para a cidadania, cf. Martha C. Nussbaum,Sem fins lucrativos, Ediçoes 70, Lisboa, 2019, p. 35 e ss.

4 Assim, Elio lo Monte, «Politicheneo-liberaliste e questione criminal ne la post-modernitá», Revista TrimestralediDirittoPenaledell'economia, anno XXIII, n. ${ }^{\circ} 4$ ottobre-dicembre, 2010 , pp. 727.

5 Sobre a situação italiana é absolutamente impressivo o «retrato» efetuado por Luigi Ferrajoli em Poderes Selvages. La crisis de la democracia constitucional, MinimaTrotta, Madrid, 20 I I, esp. pp.52-64. 


\section{A "EXPLOSÃO 2008-20| |"}

A crise despoletada em 2008, com sequência em 20 I -20 I2, foi a «explosão» do «ovo» que atingiu tudo e todos.

O que era sintoma passou a realidade. $O$ colapso financeiro que ocorreu teve consequências na economia, na política e sobretudo no tecido social de muitos países com economias pouco solidificadas ou muito dependentes ou expostas a outras. Países da Europa, como Portugal, Irlanda, Grécia, Espanha e mesmo Itália ou de outras latitudes, como o Brasil, são exemplos, ainda que diferenciados, de todas aquelas situações. Os estilhaços não mais pararam de se fazer sentir. «Anos de chumbo», na expressão acertadíssima de Eduardo Paz Ferreira6 .

As gravíssimas repercussões financeiras, económicas e sociais que atingiram diretamente os cidadãos aceleraram as fissuras do tecido social, fazendo emergir múltiplos e novos conflitos.

Um discurso político e financeiro assente em restrições orçamentais fortíssimas, ainda que balanceado com melhorias conjunturais, legitimou a redução de rendimentos de quem trabalha, a aplicação de medidas de austeridade maximalistas e sobretudo a redução ou mesmo a eliminação ou redução de direitos sociais. O empobrecimento real da maioria da população (ainda que uma minoria continue cada vez mais rica) que daí resultou o aumento do desemprego ou a precariedade laboral são apenas alguns exemplos do que ocorreu (e continua a ocorrer) em muitos países do mundo, em vários continentes.

\section{|| "A IDADE DA REGRESSÃO”}

Emolados uns poucos responsáveis pelo «crash», substituídas algumas «cabeças», os detentores dos poderes económicos e financeiros e os seus intérpretes na governação recuperaram rapidamente o seu papel na interlocução com os governos e, concretamente, o exercício "de facto" da condução e condicionamento das políticas públicas.

Alguns dos atores que, de facto, continuam a impulsionar hoje as «novas políticas» de governação, apenas retomaram lugares de responsabilidade que exerciam antes da crise de 2008.

Aqueles que criminalmente foram indiciados por terem responsabilidades de natureza criminal no despoletar da crise, porque envolvidos em crimes económicos de altíssimo valor, vêm os seus processos bloqueados ou nunca chegar ao fim, por via da sua própria capacidade financeira de utilizar e contornar o sistema legal. Poder-se-ia retomar, a este propósito, a afirmação, na prática, de um "direito penal do amigo", que permite aquela manipulação ${ }^{7}$.

6 Eduardo Paz Ferreira, Crónicas dosAnos de Chumbo, Edições 70, Lisboa, 2013

7 Expressão utilizada por Luigi Foffani, in «Escândalos económicos y reformas penales: Pre- 
Paradoxalmente continua a constatar-se um aumento das desigualdades, nomeadamente do gap entre países ricos e pobres e a não diminuição dos fenómenos de corrupção. Os dados são inequívocos: em 2017, «em todos os países da OCDE, as pessoas com baixos rendimentos dão conta de um nível mais elevado de necessidades não atendidas em matéria de cuidados médicos do que as pessoas com rendimentos mais elevados». De igual modo, refere o estudo, "os estudantes socioeconomicamente desfavorecidos têm quase três vezes mais probabilidades do que os estudantes com melhor situação económica de não alcançarem o nível de referência de competências em ciências».

De outro modo, são evidentes as cumplicidades manifestas entre interesses públicos e privados, sendo manifesta a pouca efetividade nas políticas de controlo de danos.

Daqui resulta uma diminuição drástica da confiança nas instituições públicas como mecanismos de controlo. $\bigcirc$ relatório citado da Organização para a Cooperação e Desenvolvimento Económico (OCDE) 9 , referente a 2017, é muito claro nesta matéria: «a confiança nas instituições públicas é reduzida, e a perceção de que as políticas dos governos favorecem grupos de interesses, tem aumentado acentuadamente». Nesse domínio, há uma espécie de caminho para o «grau zero» da confiança pública nas instituições.

De outra banda, emergem fenómenos de governação populista, doutrinal e substancialmente nada estruturada, mas com aparências de grande atratividade, políticas públicas restritivas de direitos fundamentais ou exacerbação de problemas sociais transnacionais nomeadamente decorrentes de migrações desordenadas.

Este continua a ser o quadro geral dos efeitos da crise. Fala-se, por isso, na «idade da regressão» ${ }^{10}$. Como se vivêssemos numa espécie de «marcha atrás» civilizacional ou num tempo de «modernização regressiva».

\section{ESTADO DE DIREITO E PODERES DE CONTROLO: TÓPICOS DIFEREN- CIADOS PARA REFLEXÃO}

Como se referiu, assume especial impressividade; no âmbito do Estado de Direito, é estabelecimento de limites jurídicos que não podem ser ultrapassados. E, por isso, devem ser enquadrados num vasto sistema de controlos mútuos.

vencion y represión de las infracciones societarias en la era de la globalization», Revista Penal, n. ${ }^{\circ} 23$, Enero 2009 , p. 37, a propósito de situações concretas que envolveram a aplicação do direito penal do mercado de valores mobiliários em Itália.

8 OCDE, Panorama das Administrações Públicas, 2017 (GOVERNMENT AT A GLANCE 2017 - ISBN 978-92-64-268739 (C) OECD 2017.

9 OCDE, Government at a Glance 2017, citado.

10 A expressão consta, em várias intervenções, na obra coletiva, L'Âge de la Regression, PremierParallelle, Paris, 2017, onde vários autores analisam, sobre várias perspetivas a situação atual decorrente das crises. 
É hoje claro que a ideia de uma sociedade autorregulada é uma utopia autodestrutiva, "incompatível com a vida social e humana"l' .

Por isso, aos vários poderes de controlo é exigido um papel essencial na sua afirmação e consolidação, ainda que executados em perspectivas e níveis diferentes e por atores diferenciados. Podemos falar, pois, de controlo social, controlo constitucional, controlo administrativo, controlo financeiro e controlo criminal.

\section{O controlo social}

Há hoje um diferente e maior escrutínio da possibilidade de controlo público de muitos fenómenos do exercício da função pública, nomeadamente da sua dimensão patológica. As redes sociais e os seus efeitos já não são apenas fiçção cientííca. O que pontualmente acontece é exponenciado para o mundo, com um conjunto de consequências.

De outra forma, a relevância dos movimentos sociais, diversificados em função de interesses também eles diversos em cada país, conforma um mecanismo de controlo efetivo de algumas políticas restritivas de direitos. O seu papel, nos últimos anos, em países, como Espanha, Grécia, Itália ou Brasil, tem sido inequívoco como mecanismo de controlo social efetivo. Muito recentemente sintomas deste controlo social começam a emergir em sociedades tradicionalmente menos abertas e sujeitas a maiores controlos das instituições públicas e governamentais, como é o caso de Hong Kong ou mesmo a Rússia.

Este controlo social assenta numa maior transparência, numa ampla troca de informações e implica maior e melhor conhecimento, o que comporta exigências de responsabilidade reforçadas para quem exerce funções públicas. Trata-se, no entanto, de um controlo que envolve riscos, nomeadamente por via da manipulação ou inverificabilidade de factos e opiniões expostas, bem como de uma expansão descontrolada e muitas vezes sem possibilidade de ser efetivamente contraditada.

\section{O controlo constitucional}

Numa dimensão de controlo institucional, num primeiro momento, funcionando como topo da "pirâmide", encontra-se o controlo de constitucionalidade das leis.

A governação pública e as suas políticas concretas estão sempre sujeitas às leis e à Constituição. $\bigcirc$ conhecimento dos limites constitucionais que naturalmente têm de moldar as políticas desenvolvidas pelos poderes públicos é o primeiro passo da legitimidade democrática da governação.

Mesmo em momentos menos consensuais, em que as políticas a tomar possam tornar mais difusos os limites da compatibilização constitucional das leis que as con-

1 Cesar Rendueles, «De la regressionglobaleauxcontremouvementspostcapitaliste», in AA.W, L'Âge de la Regression, cit., p. 262. 
sagram, deve uma boa governação saber que está sujeita ao teste da fiscalização da constitucionalidade das normas. E, por isso, não deve temê-la.

Num Estado de Direito, é nos momentos de crise que o apelo aos Tribunais nacionais para que se efetivem os direitos dos cidadãos, nomeadamente exigindo que se cumpra a Constituição, tem, porventura, o seu momento crucial.

A aplicação da Constituição tem, nesses momentos, o seu teste de relevância.

Nesse sentido, porque cabe aos Tribunais aplicar as normas de acordo com a Constituição, a judicatura é, nos momentos de crise, um suporte fundamental para a agregação dos valores e princípios que sustentam o Estado de Direito.

Como se sabe, os tribunais constitucionais funcionam como watchdog, gate keeper, ou guardiões da Constituição.

De outro modo, é função de a Constituição impor a sua força jurídica, mesmo em momentos conjunturais de crise, servindo concretamente de travão jurídico às políticas públicas que colidam com as normas e os princípios estabelecidos pelo legislador constituinte.

«A Constituição deve impor a sua força sempre, mesmo - e sobretudo - em momentos de crise», ${ }^{12}$ refere, certeiramente, Tiago Antunes.

Paradoxalmente, ou talvez não, os problemas constitucionais colocam-se, também, de uma forma quase vinculada, "fora" do Estado em duas dimensões. Numa primeira linha de compreensão, identifica-se um processo transnacional que abrange várias realidades geográficas e políticas. Numa segunda dimensão, mas em simultâneo, evidencia-se uma deslocalização dos problemas para fora do sector político institucionalizado, nomeadamente para os sectores privados da sociedade mundial.

Como consequência não podem muitos problemas, ainda que colocados num patamar constitucional nacional, deixar de ser pensados, juridicamente, numa perspectiva transnacional.

Como referiu Konrad Hesse, em maio de 1999, «o mundo do Estado Nacional soberano (...) entrou no seu ocaso. A história continuou a sua marcha afastando-se dos terrenos onde se enraizava, que até agora serviam como substrato seguro da teoria do Estado e da Constituição» ${ }^{13}$.

$\bigcirc$ que se quer salientar é que o direito constitucional emancipou-se de uma dimensão estatal e não pode hoje ser visto, fora de um quadro de proteção global dos cidadãos, para além de uma dimensão territorial específica. Nomeadamente numa perspectiva de proteção de direitos fundamentais, de direitos humanos e também de direitos sociais, que não pode ser «barrada» nas fronteiras da soberania nacional. Por

12 "Reflexões constitucionais em tempo de crise económica-financeira", in O Direito, Ano 143, V, 201 I. p. 1.098.

13 Apud Ignacio GutiérrezGutiérrez, «Derecho Constitucional para la Sociedad Multicultural» in Derecho Constitucional para la sociedade multicultural, Editorial Trotta, Madrid, 2007, p. 9. 
isso, fala-se hoje em diálogo transnacional entre os vários tribunais, nomeadamente entre tribunais constitucionais e tribunais internacionais, no âmbito da jurisdição dos direitos humanos ${ }^{14}$.

\section{O controlo administrativo}

Do ponto de vista do controlo da legalidade administrativa, a ampliação, e nalguns casos a mudança de paradigma do direito administrativo, decorrente de uma visão formalista do que foi o controlo administrativo, trouxe mudanças significativas nesse domínio.

No caso português, seguindo outras experiências europeias, essa mudança trouxe consigo duas perspectivas significativas. De um lado, o alargamento da legitimidade ativa do controlo administrativo ao cidadão, nomeadamente por via da ação coletiva, quando estão em causa interesses difusos. Questões como a tutela ambiental, o direito à saúde, o direito à segurança pública, entre outros passaram a permitir a validação judicial por iniciativa dos cidadãos.

Por outro lado e numa segunda dimensão, o próprio âmbito da intervenção jurisdicional referente ao controlo da legalidade dos atos da administração foi ampliado, nomeadamente no que tange à amplificação da tutela cautelar, subjacente à atividade e concretização de determinados atos administrativos ${ }^{15}$.

Essa ampliação comporta riscos. De um lado no âmbito da delimitação de fronteiras com consequências diretas no âmbito das restrições das políticas públicas, nomeadamente no grau de autonomia do próprio poder legislativo na concretização das políticas públicas. Doutro, por aquilo que alguns autores configuram como o "uso excessivo e abusivo dos meios cautelares» ${ }^{16}$ e uma consequente possibilidade de «paragem» da atuação e intervenção pública.

\section{O controlo financeiro}

Numa outra dimensão, podemos identificar o controlo financeiro, ainda que subdividido na vertente das finanças públicas e na vertente relacionada com a economia.

14 Como exemplo de diálogo entre o Tribunal Europeu dos Direitos Humanos os vários tribunais nacionais mas também para o Tribunal Constitucional, cf. Sousa Ribeiro, «Encontros e desencontros ente a jurisprudência do Tribunal Europeu dos Direitos Humanos e a jurisprudência nacional», Revista de Legislação e Jurisprudência, Ano I48 n. ${ }^{\circ}$ 40। 4, 2019, p. 142 e 162.

15 Sobre este ponto, cf. Ana Gouveia Martins, «Efectividade da tutela cautelar», in Cadernos de Justiça Administrativa, n. ${ }^{\circ}$ 124, Julho/Agosto de 20 17, p. 3 e Marco Caldeira, "A efetividade da tutela cautelar: algumas notas sobre o regime da execução das decisões cautelares administrativas», Cadernos de Justiça Administrativa, n. ${ }^{\circ}$ 124. Julho/Agosto, 20 17, p. 72.

16 Assim, Tiago Duarte, «Providências cautelares, suspensões automáticas e resoluções fundamentadas: pios a emenda que o soneto», JULGAR, n² 26, Maio/Agosto, 20 I 5, p. 78. 
A importância financeira nos esquemas organizatórios dos Estados ultrapassa a dimensão estrita e meramente pecuniária do tradicional discurso financeiro. As finanças são o «nervo financeiro da República», na expressão de Canotilho ${ }^{17}$.

A exigência da boa governação dos dinheiros públicos, por via de controlos orçamentais efetivos, assume-se hoje como uma realidade essencial.

A consciencialização social da dimensão pública dos recursos financeiros disponíveis, que são sempre reduzidos, nomeadamente por via de a sua fonte resultar, essencialmente, de rendimentos dos cidadãos e das empresas, ainda que por via de impostos indiretos, comporta uma nova exigência do modo como a sua aplicação é concretizada. A sua gestão eficiente e eficaz assume hoje um conteúdo efetivo. Não se trata apenas do controlo de legalidade, mas também das dimensões da economia, eficiência e eficácia das opções políticas com repercussão económica. Ultrapassa-se o mero controlo formal de legalidade estrita, questionando não as opções, mas a sua sustentação económica e as suas consequências. Princípios como a equidade intergeracional, ou a sustentabilidade económica das opções políticas são hoje chamados a configurar critérios de legalidade financeira.

Neste último sentido, as gerações futuras não podem ficar hipotecadas de escolhas e opções não sustentadas ou assentes em justificações de interesses de curtíssimo prazo.

É nesse enquadramento que o controlo efetuado pelos Tribunais de Contas se assume como absolutamente relevante na boa gestão dos dinheiros públicos.

Os Tribunais de Contas são instituições de controlo externo fundamentais no sistema de controlo de fundos públicos.

As competências jurisdicionais atribuídas para efetivar a responsabilidade financeira decorrente de mau uso de dinheiro público estão repartidas por entidade e jurisdições diferenciadas nos vários países.

Em França, Itália, Espanha, Portugal, Brasil e muitos países da América Latina ainda que com quadros jurídicos diferenciados, é aos Tribunais de Contas que compete, em determinados domínios, efetivar a responsabilidade financeira decorrente de mau uso de dinheiro público. Sempre, naturalmente, com a salvaguarda das competências criminais que as mesmas matérias podem comportar e que, nesse caso, estão atribuídas ao Ministério Público, e em regra aos tribunais comuns.

A Jurisdição de Contas, como jurisdição exclusiva e especial para apreciar e julgar a responsabilidade financeira, existe exatamente para resolver de modo eficaz, sem os inconvenientes da natureza invasiva e de ultima ratio do direito penal, e em termos adjetivos do processo penal ${ }^{18}$, as patologias que afetam a gestão e o uso de di-

17 J.J. Gomes Canotilho, «Incomensurabilidade dos discursos ou hierarquias entrelaçadas nos sistemas jurídicos multinível», Católica LawReview, Janeiro 2017, Volume I, n. I, p 39.

18 Claramente neste sentido, cf. Pelino Santoro, L'lllecitoContabile e La responsabilità amministrativa, Maggioli Editores, 201 I, p.78. 
nheiro público. $\bigcirc$ que não quer dizer que a responsabilidade financeira não tenha de ter subjacente uma dimensão garantística sustentada em regras pré-definidas, quer quanto à tipicidade e âmbito da infração, quer mesmo de um ponto de vista procedimental. Que não tem de ser sobreposto ao sistema penal. Salienta-se sobre esta diferenciação, e a sua repercussão no quadro jurídico da Convenção Europeia dos Direitos Humanos, a importante decisão do Tribunal Europeu dos Direitos Humanos (caso Rigolio c. Italia, de |4.5.20 I4) ' $^{19}$ em que se entendeu inexistir violação do artigo $7^{\circ}$ da Convenção num caso em que o procedimento perante o Tribunal de Contas Italiano em que estava em causa um montante imputado ao recorrente no âmbito de uma questão financeira, a sua natureza ressarcitória não sendo de natureza penal, não implicava a aplicação e consequente violação do referido artigo.

No que respeita à regulação financeira, autores como Teubner, tendo em conta a existência de mercados financeiros globais, defendem uma reforma monetária que, em última análise, «requer soluções constitucionais globais», assente na «cooperação entre os bancos centrais» ${ }^{20}$.

Do ponto de vista económico, os princípios que conformam a defesa da propriedade, do contrato, da concorrência, como institutos que representam os pilares fundantes das constituições económicas, devem ser juridicamente salvaguardados, de modo a evitar distorções ou apropriações por parte de mercados desregulados.

A economia e as finanças, ainda que sustentadas nos princípios que lhes são próprios, necessitam de mais controlo da parte do direito, nunca de uma redução do direito.

Os controlos de legalidade, tanto por via das instituições financeiras de regulação, como os Bancos centrais são hoje mecanismos essenciais ao controlo da dimensão financeira do Estado, que, como se sabe tem repercussões em todo o espectro da governação. São, por isso, uma dimensão essencial do Estado de Direito.

\section{O controlo criminal}

Numa última dimensão, importa atentar à política criminal como mecanismo essencial do controlo, nomeadamente na prevenção e repressão de patologias criminais que concretamente atingem a dimensão do Estado e da sua governação.

Salientamos, muito particularmente, as respostas exigidas às consequências das patologias da governação decorrentes da corrupção, ainda que vistas num sentido amplo.

19 Desenvolvidamente, José Mouraz Lopes, «O processo de responsabilidade financeira diante do Tribunal de Contas, à luz da Convenção Europeia dos Direitos Humanos», in AAW, Comentário à Convenção Europeia dos Direitos Humanos, Universidade Católica, Lisboa, 2019 (no prelo).

20 GuntherTeubner, Nuoviconfliticostituzionali, Bruno Mondadori, Milano, 20 I2, p. 107 
O conceito amplo de corrupção, comporta "todo e qualquer abuso de poder em benefício próprio" ${ }^{11}$, no sentido dado pelo Relatório da Comissão ao Conselho e ao Parlamento Europeu22.

Tal conceito não reduz a exigência de tratar, em termos substantivos, a matriz jurídico-penalmente relevante que pode comportar vários tipos criminais que abrangem, entre outros, a corrupção stricto sensu, o tráfico de influências, a participação económica em negócio, a concussão, o abuso de poderes, o branqueamento de capitais e mesmo crimes que envolvem outros bens jurídicos, como sejam a corrupção no desporto ou a criminalidade fiscal.

A utilização de um conceito elástico como o referido permite maior operatividade das políticas públicas anti-corrupção, nas suas dimensões preventiva e repressiva, não necessariamente penal, levadas a termo pelas diversas instituições que, nesse âmbito, têm intervenção de acordo com as suas competências.

Poderíamos sintetizar, nesse âmbito, a necessidade de ser feito um reforço ou enforcement mais efetivo, de modo a, por um lado, evitar a sua disseminação (prevenção), e, por outro, reforçar e tornar mais efetivo o sistema de repressão.

Desde logo a sua compatibilização com o reforço de competências dos órgãos de fiscalização interna da administração, tanto por via da sua maior autonomia e independência como do reforço dos seus poderes e meios de atuação.

Igualmente a interligação entre todas as entidades que se entrecruzam no processo de fiscalização e monitorização, permitindo cruzar e partilhar informações. $\bigcirc$ "enforcement" das entidades fiscalizadoras e reguladoras assume, por isso, uma relevância inquestionável.

No que respeita ao sancionamento das patologias dos sistemas financeiros, deveria pensar-se em sistemas de controlo e reação também eles excecionais, nomeadamente em termos de resposta imediata, em que os mecanismos procedimentais, sem porem em causa direitos fundamentais, têm de ser muito mais eficientes e eficazes. Por isso, procedimentos semelhantes a providências cautelares imediatas, bloqueios e sanções sustentados em sistemas probatórios, também eles excecionais, são algumas das soluções que se podem encontrar. Situações que, no entanto, não necessitam de passar exclusivamente pelo direito penal.

No que respeita aos conflitos de interesses e concretamente ao revolving door, têm de ser ultrapassados os débeis mecanismos de controlo sobre as situações que

21 Aprofundadamente, José Mouraz Lopes, O Espectro da Corrupção, Almedina, Coimbra, 2011 .

${ }^{22}$ Cf. O primeiro RELATÓRIO DA COMISSÃO AO CONSELHO E AO PARLAMENTO EUROPEU RELATÓRIO ANTICORRUPÇÃO DA EU, Bruxelas, 20I4, in c.europa.eu/dgs/ home-affairs/e-library/documents/policies/organized-crime-and-human-trafficking/corruption/ docs/acr_2014_pt.pdf. 
envolvem esse tipo de permeabilidade, nomeadamente a fragilidade institucional das entidades que regulam e fiscalizam as matérias relativas a incompatibilidades de cargos públicos, bem como alguma tolerância social que envolvem.

Finalmente, há ainda áreas de risco, diversificadas, que impõem tratamentos diversificados. Áreas como a contratação pública, pelos valores e riscos que comportam, devem estar sujeitas a mecanismos que impeçam todos os desvios de legalidade e permitam o consequente alerta que deve ser dado, a partir daí às autoridades. Estamos aqui no domínio dos chamados "whistleblowing" que são mecanismos de alerta aprofundados e com enorme relevância prática.

Ainda no âmbito do controlo do funcionamento do sistema de investigação criminal, é possível criar respostas rápidas, eficazes e mesmo economicamente mais sustentadas no domínio das técnicas e dos métodos de investigar crimes e mesmo para o seu julgamento, nomeadamente no âmbito de toda a criminalidade complexa que, no âmbito da corrupção, normalmente está em causa.

No âmbito da gestão da investigação criminal, nesta matéria, assume especial relevância a assertividade da gestão do inquérito, pela identificação do seu objeto, restringido a sua efetiva capacidade de prova, que é pouco compatível com «mega processos», cuja dificuldade de gestão é evidente. Uma investigação só é eficaz se se circunscrever ao objeto do processo, que não pode ser constantemente alargado ao sabor de informações esparsas que vão surgindo na investigação e que, sem uma triagem imediata, tornam o inquérito ingovernável.

De igual modo a opção por investigações «cirúrgicas» e dotadas de mais celeridade, utilizando-se o mecanismo da «separação de processos» como instrumento útil de gestão, não parece colidir com o princípio da legalidade que deve orientar toda a atuação do Ministério Público, desde que asseguradas todas as garantias de defesa inerentes.

\section{CONCLUSÃO}

A democracia não é apenas um sistema de governo. Nas palavras de Tawneya, democracia deve ser também «um tipo de sociedade e uma forma de vida em harmonia com esse modelo social» ${ }^{23}$.

modelo democrático, no que respeita ao exercício da gestão pública, exige uma intervenção de amplos controlos pelas várias instituições do Estado, permitindo enquadrar a sua dimensão transnacional, os sistemas público e privado, e sobretudo que leve em conta as exigências públicas de transparência devida aos cidadãos.

Como referem alguns estudos da Organização para a Cooperação e Desenvolvimento Económico (OCDE) ${ }^{24}$, «o reforço da integridade das instituições do governo

23 Richard Tawney, Equality, New York, Harper, 1931.

${ }^{24}$ Cf, OCDE, Panorama das Administrações Públicas, 2017 (GOVERNMENT AT A GLANCE 2017 - ISBN 978-92-64-268739 (C) OECD 2017) 
e dos representantes eleitos, o estabelecimento de um diálogo contínuo com os cidadãos através de métodos de elaboração de políticas abertos e participativos e o fortalecimento da capacidade do governo para escolher as políticas mais adequadas entre várias opções, são, todos eles, essenciais para reaproximar os governos dos seus cidadãos e fomentar um crescimento mais inclusivo e sustentável».

Cidadãos que querem apenas ver efetivado o bom governo por aqueles em quem votaram para esse efeito.

Recebido em: 29/07/2019

Aprovado em: 03/09/2019 
